\title{
AMBIEENCIA ANIMAL E AS PERDAS PRODUTIVAS NO MANEJO PRÉ-ABATE: O CASO DA AVICULTURA DE CORTE BRASILEIRA
}

\author{
ANIMAL AMBIENCE AND PRODUCTIVE LOSSES ON THE PRESLAUGHTER HANDLING: \\ THE BRAZILIAN POULTRY PRODUCTION CASE
}

\author{
Silva, I.J.O. ${ }^{1 *}$ e Vieira, F.M.C. ${ }^{1}$
}

${ }^{1}$ Núcleo de Pesquisa em Ambiência (NUPEA/ESALQ-USP). Departamento de Engenharia de Biossistemas. Av. Pádua Dias, 11. Caixa postal 09. CEP:13-418-900. Piracicaba. São Paulo. Brasil. *ijosilva@esalq.usp.br

\section{Palavras chave adicionais}

Abatedouro. Frangos de corte. Logística avícola.

\section{RESUMO}

A evolução dos estudos sobre a ambiência na avicultura de corte tem alcançado patamares notáveis no que diz respeito às informações sobre a qualidade do ar, o ambiente térmico, acústico e lumínico nas diferentes fases de criação de frangos de corte. No entanto, pouca preocupação é dada à fase entre a retirada do animal da granja e o abate, ou seja, o manejo pré-abate, o que explica a elevada proporção de perdas produtivas nesta etapa. As informações sobre as condições ideais são escassas, principalmente considerando as condições climáticas críticas em regiões tropicais, como é o caso do Brasil Consequentemente, as perdas por mortalidade pré-abate podem ultrapassar $1 \%$ ao longo do ano, resultando em grande prejuízo para todos os segmentos da cadeia avícola. Visando a redução de perdas nas operações pré-abate de frangos de corte, o levantamento de estudos e informações úteis é necessário, para que seja possível a padronização de procedimentos de manejo. O objetivo desta revisão é abordar pontos importantes que possam nortear a redução de perdas no manejo pré-abate da avicultura de corte, no que diz respeito aos fatores que influenciam nas perdas por mortalidade, no transporte de frangos da granja até o abatedouro, na espera no abatedouro e as principais soluções científicas desenvolvidas na ambiência e logística avícola.

\section{SUMMARY}

The evolution of the studies concerning ambience on poultry production has reached

\section{AdDitional KEYWORDS}

Abattoir. Broiler chicken. Poultry logistics.

remarkable levels concerning information about air quality, thermal, acoustic and lightning environment in the different stages of poultry raising. However, little is known about the stage between the animal removal from farm and the slaughter, in other words, the preslaughter handling, which explain the high proportion of productive losses in this stage. The information about the ideal conditions is scarce, mainly considering the critical climatic conditions in tropical regions, as is the case of Brazil. Thus, the preslaughter mortality losses may exceed $1 \%$ throughout the year, resulting in great economic losses for all segments of the poultry production system. Aiming the reduction of losses on poultry preslaughter operations, the survey studies and useful information is necessary, to be feasible to standardize the management procedures. The objective of this review is to address important issues that can guide the reduction of losses during preslaughter operations of poultry production, with regard to the factors that influence the mortality losses, in the poultry transport from farm to the abattoir, in the lairage stage and the main scientific solutions developed in the ambience and poultry logistics.

\section{INTRODUÇÃO}

Diante da evolução científica e tecnológica na qual estamos inseridos atualmente, as tendências mundiais para um desenvolvimento sustentável faz com que a visão dos profissio- 


\section{SILVAE VIEIRA}

nais que atuam na área de ambiência animal seja direcionada para novos horizontes. Esses novos caminhos ultrapassam as fronteiras da propriedade rural, ou empresa de produção de proteína animal e focalizam as perdas produtivas ao longo de todo o processo produtivo.

São comuns hoje os profissionais voltados para o estudo da ambiência animal associada ao conforto térmico nos ambientes, galpões de produção e para o bem-estar dos animais nas diferentes instalações e sistemas produtivos. O bem-estar animal pode ser definido como o estado de um indivíduo em relação às suas tentativas de se adaptar ao seu ambiente (Broom, 1986). Contida neste conceito, a ambiência exerce grande influência na adaptação do animal ao ambiente no qual se encontra inserido. Segundo Paranhos da Costa (2000), o conceito amplo de ambiência pode ser descrito como o meio físico e psicológico nos quais o animal realiza suas atividades. Posteriormente, Paranhos da Costa (2002) completou o conceito de ambiência como o estudo do ambiente que envolve o animal, englobando seu espaço físico e social e tudo que está incluso neste espaço, inclusive nós. A ambiência também pode ser definida como a soma dos impactos dos fatores biológicos e físicos nos animais, consistindo-se em um dos principais responsáveis pelo sucesso ou fracasso do sistema de produção avícola (Macari e Furlan, 2001). Nota-se que os conceitos de bem-estar animal e ambiência estão estreitamente ligados, consistindo em elementos importantes dos principais problemas e soluções da produção animal.

Com relação à ambiência, existe uma busca ainda desenfreada de informações no que tange a qualidade do ar, ambiência térmica, acústica e lumínica, porém mesmo assim existe uma carência de informações relacionadas à continuidade do processo além das unidades produtoras.

As perdas produtivas são cada vez mais contabilizadas no sentido de reduzir os prejuízos e conseqüentemente aumentar da rentabilidade, uma vez que, os consumidores estão cada vez mais exigentes com a qualidade do produto final. Todavia, a qualidade do produto será o próximo horizonte a ser alcançado, visto que são necessários mais atributos que possam conferir a segurança dos alimentos. Estas exigências, por sua vez, trarão mudanças e a necessidade do conhecimento dos muitos pontos críticos inerentes aos processos, para que tais modificações resultem em aumento de produtividade e numa maior inserção do produto brasileiro no mercado.

Nesse sentido, nosso objetivo foi abordar a ambiência no manejo pré-abate, ou seja, no momento em que os animais estão "prontos" para o abate e são encaminhados para os frigoríficos (no caso de aves, bovinos e suínos, por exemplo). Nesse caso especificaremos o caso da avicultura brasileira, uma vez que se trata de uma cadeia do agronegócio que emprega alto nível tecnológico e cuja ambiência animal galga altos patamares de evolução com ótimos resultados refletidos na produção.

Uma das preocupações mais urgentes da avicultura brasileira refere-se às perdas ao longo do processo produtivo. Em sentido contrário ao crescimento do setor no mercado interno e externo, os prejuízos anuais são expressivos, ultrapassando milhões de reais, incompatíveis com a competitividade da avicultura neste cenário. Assim, os esforços devem ser direcionados para a redução de perdas, visando aumento da lucratividade do produto final, pautado no contexto atual de bem-estar animal. A identificação das perdas localizadas durante as operações pré-abate torna-se um ponto crucial na otimização dos processos de produção. Atrelar estes conhecimentos à redução de perdas é fundamental atualmente, pois se trata do acompanhamento de observações técnicas das operações do chamado seguimento "manejo pré-abate". Enquanto várias são as pesquisas direcionadas para o segmento de "dentro da 
porteira", pouca coisa se sabe sobre o que realmente ocorre com as aves após deixarem as granjas. Para isto, existe a necessidade de se localizar com precisão os gargalos produtivos ao longo do processo, principalmente nas operações pré-abate de frangos de corte, onde o nível de informação a respeito das boas práticas de manejo ainda é baixo.

Existem perguntas a cada momento relacionadas com o conjunto de operações no chamado "manejo pré-abate". A grande maioria dos olhares está voltada para os problemas relacionados aos sistemas de criação e aos 42 - 45 dias de criação dos frangos numa granja e seus índices zootécnicos. Ao sair da granja propriamente dita, várias são as perguntas sem respostas que encontramos para evitar as perdas nessas etapas seqüenciais. Qual a melhor densidade por caixa nos carregamentos? Qual o melhor horário de transporte em períodos de estresse e quais os verdadeiros reflexos nas perdas mensuráveis? Como é a condição climática nas carrocerias dos caminhões transportadores? Essas perguntas e mais uma série de outras, nem sempre têm uma resposta imediata com dados reais, visando à identificação pontual do problema, com medidas paliativas ou preventivas para resolvê-las.

\section{PERDAS PRÉ-ABATE DE FRANGOS DE CORTE}

De acordo com Broom (1998), o bemestar de um animal varia de pobre a rico, bem como ruim a bom. Dentre os principais tipos de perdas pré-abate, tais como lesões, contusões, fraturas, alterações negativas nos parâmetros de qualidade da carne, dentre outros, a mortalidade é o indicador mais extremo da falta de bem-estar, ou seja, a morte de algumas aves indica problemas severos para muitas outras (Nicol e Scott, 1990). O número de aves mortas é o único indicador que oferece às empresas integradoras informações importantes so- bre as condições oferecidas aos animais durante as operações pré-abate (Broom, 1993). Segundo o mesmo autor, outros indicadores também podem ser utilizados, como incidência de ossos quebrados e parâmetros fisiológicos, como por exemplo, a temperatura retal. No entanto, as chamadas mortes na chegada (death on arrival - DOA) possuem maior impacto econômico no setor e por isto, merecem maior destaque nesta discussão a seguir.

As perdas por mortalidade podem ultrapassar $1 \%$, sendo que $40 \%$ das perdas são em função do estresse térmico (Ritz, 2003). O aceitável é a mortalidade por volta de 0,1 a $0,5 \%$. No entanto, as perdas por morte registradas na maioria dos casos se encontram acima de $0,6 \%$. À primeira vista, uma proporção desta magnitude parece ser desprezível, diante da quantidade de aves transportadas em um caminhão (acima de três mil aves). Entretanto, quando se considera a quantidade de caminhões que chegam aos abatedouros por dia, dentro de um ano, os prejuízos tomam dimensões maiores.

Com destaque no transporte, as condições geralmente são inaceitáveis, contribuindo efetivamente desde o aumento do estresse no lote até a mortalidade (Nijdam et al., 2004; Barbosa Filho, 2008; Vieira, 2008). Nicole Scott (1990) reportaram em seus estudos que os potenciais fatores causadores de estresse no transporte incluem desde as características térmicas do micro clima da carga, aceleração ou vibração das caixas, impactos, velocidade do vento, jejum e até a quebra da estrutura social.

\section{ORGANIZAÇÃO PARA O TRANS- PORTE}

\section{DENSIDADE DE AVES POR CAIXA}

A densidade de aves por caixa é decidida na fase de pega e normalmente a quantidade de animais que são transportadas no lote visa a praticidade e economia 


\section{SILVAE VIEIRA}

quanto ao tempo gasto pelos operadores na granja, além da redução do número de caminhões utilizados no transporte. Varia geralmente entre 5 a 10 aves por caixa e pode ser que sejam adotadas diferentes densidades dentro de um mesmo lote, em função do número de aves restantes no último galpão a ser esvaziado.

Vieira (2008), analisando os dados referentes à densidade de caixa num carregamento noturno (figura 1) verificou que há uma variação na mortalidade dos animais em diferentes faixas de densidade. Existe um limite entre 3 a 7 aves por caixa em que a mortalidade neste turno foi reduzida até a mortalidade mínima nas densidades de 7 aves. Nota-se que com a redução da densidade, houve um acréscimo na mortalidade. Nesta situação, a ave já apresenta troca de energia térmica na forma de calor sensível (condução, convecção e radiação) com o ambiente, segundo Furlan e Macari (2002), e o organismo dela tenta compensar através dos mecanismos de termogênese (tremor,

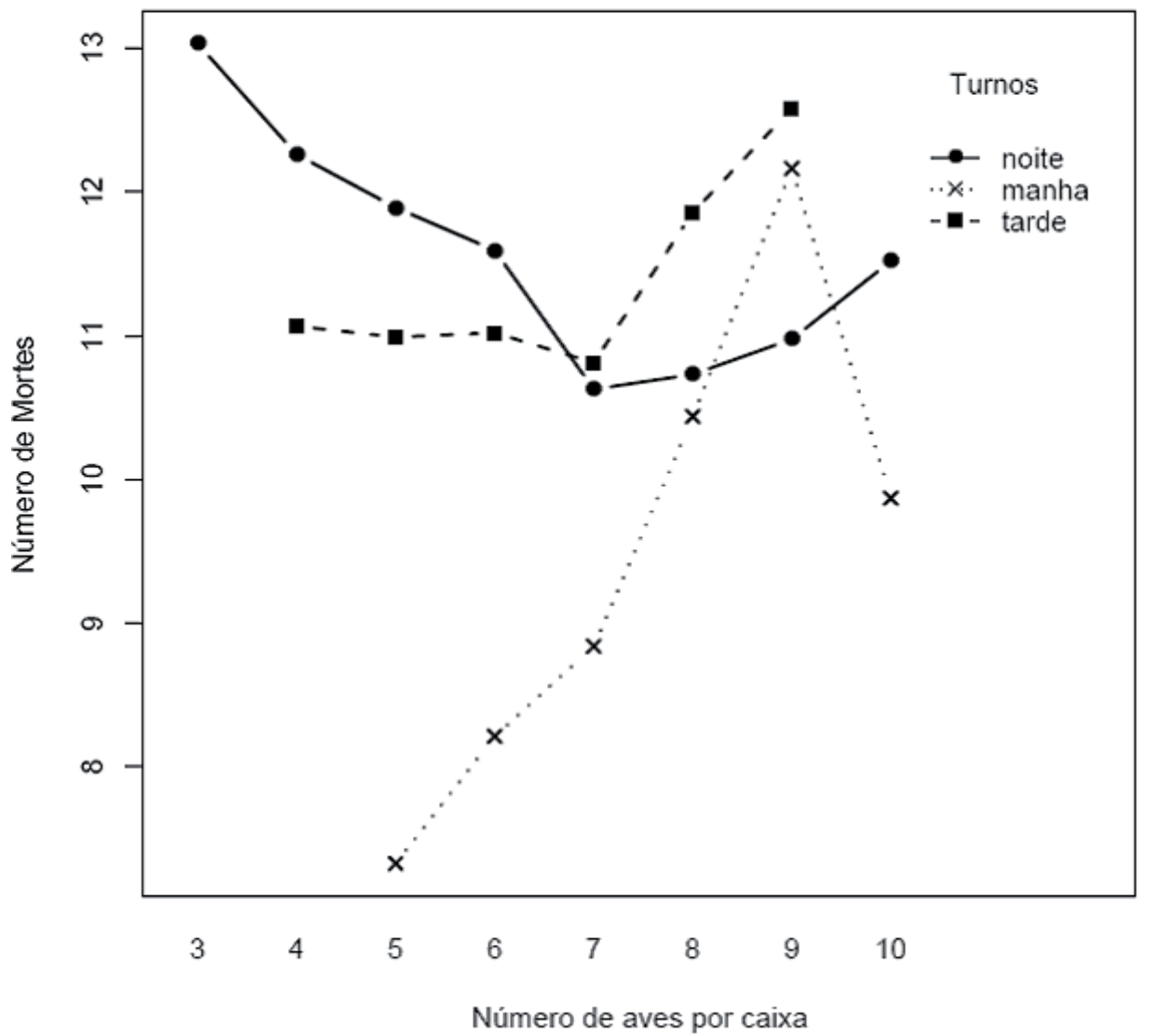

Figura 1. Valores médios da interação entre o número de aves por caixa e os diferentes turnos, em relação ao número de aves mortas (Vieira, 2008). (Mean values of the interaction between the number of birds per cage and the different daily periods, in relation with the number of dead birds (Vieira, 2008)). 
vasoconstrição periférica e eriçamento das penas), com o objetivo de diminuir a transferência da energia térmica para o meio.

Porém, acima de 8 aves por caixa, houve um pequeno incremento no número de aves mortas. A influência deste fator no bemestar das aves refere-se à quantidade de calor produzida por elas nesta fase. Densidades maiores refletem em grande produção de calor e em dias quentes, o problema se torna bem maior, pois a quantidade de calor é alta, bem como a de vapor d'água, resultando em aumento da umidade relativa (Delezie et al., 2007). Quando isto acontece, as aves apresentam dificuldades de trocas térmicas com o meio, aumentando o estresse térmico e conseqüentemente as perdas por mortalidade. Conforme Kettlewell (1989), quanto maior a densidade de aves por caixa, mais comprometida estará a perda de calor sensível, com exceção das aves que se encontrarem nas extremidades da carga, onde a maior ventilação desta região favorecerá a ocorrência de menores perdas (DOA).

De forma geral, de acordo com os resultados de Vieira (2008) pode se dizer que em relação às densidades elevadas (acima de 7 aves por caixa), houve um acréscimo na mortalidade no turno da tarde, seguido do turno da manhã e noite, devido à temperatura elevada nos dois primeiros turnos, conjugada com o efeito da umidade relativa. Nas densidades menores (abaixo de 7 aves por caixa), a mortalidade foi elevada no turno da noite, seguida pelo turno da tarde e pelo turno da manhã, por causa do efeito da perda de calor sensível no turno da noite. $\mathrm{O}$ número de aves mortas foi menor devido ao espaço maior para troca térmica dentro das caixas, que favorece as aves nestes períodos.

Quanto aos melhores turnos para se realizar as operações pré-abate, Nijdam et al. (2004) encontraram maiores taxas de mortalidade na manhã e na tarde e as menores perdas durante a noite, recomendando o manejo pré-abate no intervalo entre 0 e 5 horas. Quanto à densidade de aves por caixa, Delezie et al. (2007) recomendaram um espaço ideal de aproximadamente $576 \mathrm{~cm}^{2}$ por frango, o que nas medidas encontradas nas caixas adotadas no abatedouro $(70 \times 60$ $\mathrm{cm})$, equivale à faixa de densidade entre $7 \mathrm{e}$ 8 aves por caixa. Todavia, devem-se considerar tais recomendações em cada turno em que o transporte foi realizado.

Sendo assim, de acordo com a literatura avaliada, pode-se recomendar como dicas para um melhor manejo, que as melhores densidades de aves por caixa relacionadas com as menores perdas em cada turno foram 5 aves por caixa no turno da manhã e 7 aves no turno da tarde e durante a noite (tabela I).

Há necessidade de maiores estudos no sentido de indicar para as empresas manejos adaptados a realidade das mesmas.

\section{A ASPERSÃO DE ÁGUA ANTES DO TRANS- PORTE}

Este recurso ainda é um ponto controverso no meio avícola, uma vez que todos o adotam nas etapas de carregamento e pouca informação é dada a respeito deste manejo. A justificativa para a aspersão de água na carga antes do transporte é a redução de calor no lote, favorecendo o conforto térmico nas horas mais quentes do dia. No entanto, observa-se na maior parte das situações que os operadores molham a car-

Tabela I. Valores recomendados de densidade de aves por caixa em cada turno e suas respectivas taxas de mortalidade (\%) esperadas. (Recommended values of density of birds per cage for each daily period and its respective expected mortality rates $(\%))$.

\begin{tabular}{lcc}
\hline Turno & aves por caixa & mortalidade esperada \\
\hline Manhã & 5 & 0,30 \\
Tarde & 7 & 0,32 \\
Noite & 7 & 0,31 \\
\hline
\end{tabular}

(Fonte: Vieira, 2008).

Archivos de zootecnia vol. 59 (R), p. 117. 


\section{SILVAE VIEIRA}

ga independente do horário e condição, seja de noite ou nos demais períodos e com isto, as perdas podem sofrer influência do mau uso deste recurso.

A condição térmica básica para molhar a carga deve ser a de temperatura ambiente elevada e umidade relativa baixa. Ou seja, umidade elevada (acima de $85 \%$ ) certamente dificultará as trocas térmicas das aves, pois a evaporação da água passa a ser limitada em função da quantidade de vapor d'água na atmosfera. Caso seja a opção a aspersão, deve-se ter muita atenção com a uniformidade de aplicação da água. Deixar a mangueira ligada em um ponto só da carga, favorece a desigualdade de umidade na carga, promovendo os chamados núcleos ou "bolsões" térmicos. O motorista ou o operador desta etapa deve molhar todas as partes igualmente, sem encharcar pontos específicos. No inverno ou em dias e horários mais frios, deve ser suspensa a atividade, para não provocar estresse por frio nas aves.

\section{OTRANSPORTE}

\section{MicROCLIMA DA CARGA}

Quanto à distribuição das mortes ao longo da carga, conforme Hunter et al. (1997), é sabido que não só as condições microclimáticas desta afetarão o número de mortes durante o transporte, visto que injúrias pré-existentes, bem como patologias, poderão exercer influência sobre estes valores. No entanto, Mitchell e Kettlewell (1998), e posteriormente Hunter et al. (2001), estudaram o perfil térmico de uma carga de frangos durante o transporte e relataram heterogeneidade existente ao longo do lote, formando um núcleo térmico em diferentes pontos. Isto se deve em função de algumas barreiras existentes, como por exemplo, a cabine do caminhão, o posicionamento das caixas com a formação de uma fileira intermediária (quando a conformação da carga possui três fileiras longitudinais), bem como as próprias aves no interior das caixas. A ventilação é desuniforme, tendo mais efeito nas caixas diretamente expostas ao vento (as caixas de cima, na parte superior e frontal do caminhão, por exemplo) e menor nas camadas do meio. Em estudo realizado recentemente no Brasil, Barbosa Filho (2008) relatou a ocorrência destes "bolsões" térmicos em vários pontos da carga, relacionados com a menor ventilação nestes locais. O autor ainda afirmou que a ocorrência das mortes se deu em maior proporção na parte central e traseira do caminhão, regiões inadequadas sobre o ponto de vista de condições bioclimáticas. É evidente que as variações estão correlacionadas com o período do ano e o turno em que esse material foi transportado, porém, deve-se considerar as variações existentes nas diferentes condições e avaliar o pior cenário. De acordo com Barbosa Filho (2008) o pior cenário dentre vários estudados está relacionado com a distância de deslocamento, tempo de viagem, turno em que essa viagem ocorreu e em qual a época do ano. Na figura 2 é ilustrado o perfil de um carregamento realizado no período do verão, no turno da manhã e numa distância considerada longa $(>100 \mathrm{~km})$.

Por meio da distribuição espacial das variáveis climáticas indicadas no perfil, percebe-se que a heterogeneidade passa por um processo dinâmico a cada instante e diretamente relacionadas com as condições do clima, transporte, velocidade dos ventos e do veículo. Baseando-se nos diferentes cenários analisados por Barbosa Filho (2008) verificam-se os principais locais de micro clima mais desfavoráveis as aves numa carga durante o transporte. Nos estudos do autor ficou evidenciado que tanto para o período de inverno como no verão a região central da carga de um caminhão, ainda continua sendo a de pior condição microclimática para as aves.

Sob esse aspecto vale ressaltar a importância que deve ser dada a logística de distribuição de carga viva, pois, todos os 

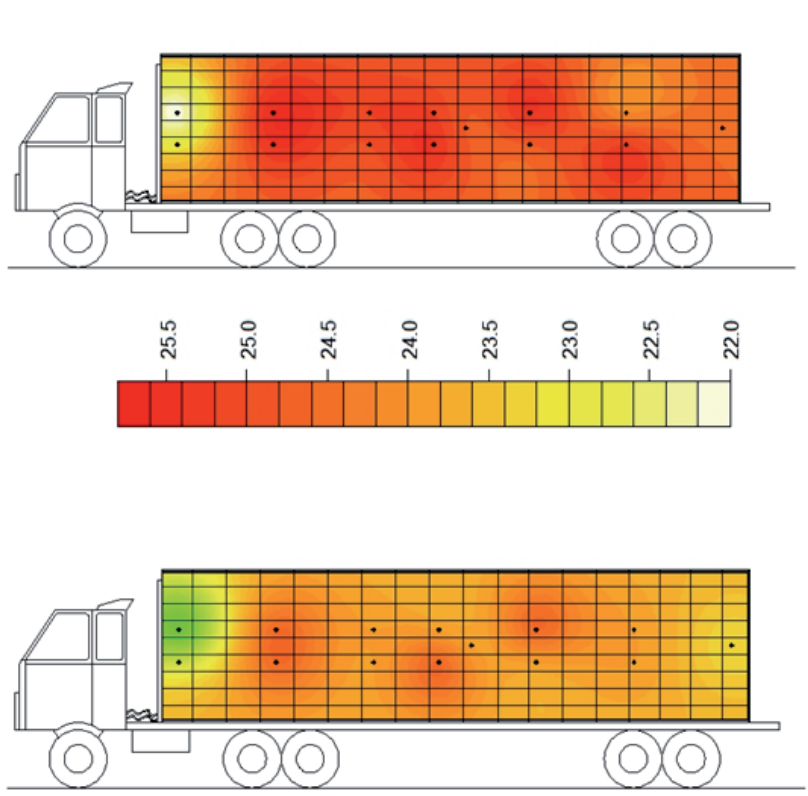

ఫั
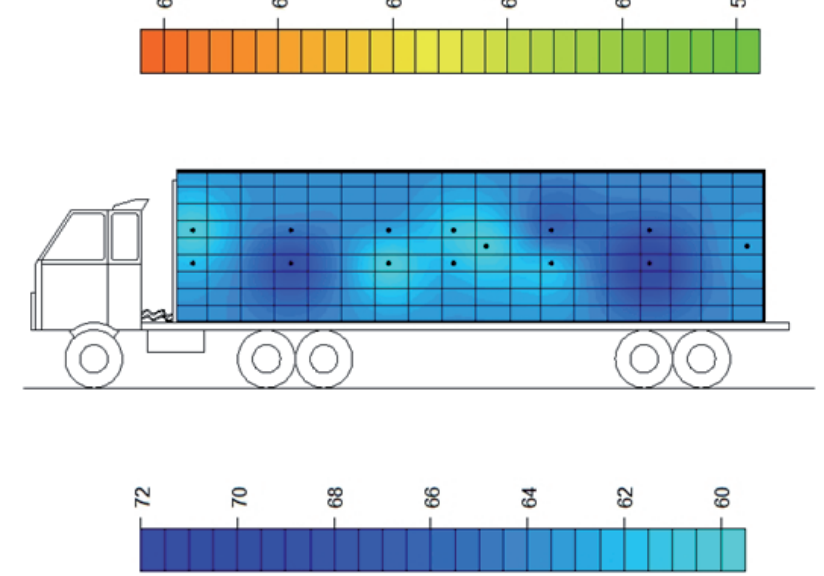

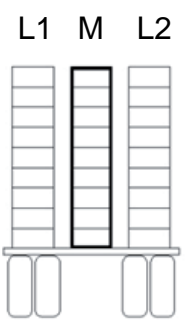

Temperatura ${ }^{\circ} \mathrm{C}$

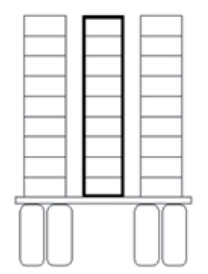

Entalpia $\mathrm{kJ} / \mathrm{kg}$ ar seco

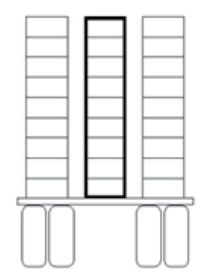

Umidadde relativa $(\%)$

Figura 2. Perfis dos comportamentos da variável ambiental temperatura (MTemp.) e do Índice Entalpia de Conforto $(\mathrm{MH})$ ao longo da fileira do meio, para um cenário de verão, distância longa, turno da manhã e sem aspersão de água na carga antes do transporte (Barbosa Filho, 2008). (Profile of dry-bulb temperature (MTemp) and Enthalpy Comfort Index (MH) throughout the middle stack, for a scenario of summer, long distance, morning and without water sprinkling on the load before the broiler transport (Barbosa Filho, 2008)). 


\section{SILVAE VIEIRA}

fatores interferem na eficiência do processo e na redução das perdas nessas operações. O que se encontra na literatura são modelos para cargas inanimadas, o que praticamente não apresentam o mesmo nível de complexidade.

\section{ESTAÇÕES DO ANO E PERÍODOS DO DIA}

Hoje em dia, com as mudanças no clima e na distribuição térmica ao longo do ano, torna-se difícil a delimitação de estações, pois mesmo no inverno, em determinadas regiões do país, é registrada a ocorrência de dias quentes, assim como temperaturas baixas nas meias estações ou até mesmo no verão. Porém, os transportes de frangos de corte são realizados todos os dias do ano, independente da estação, e com isto observa-se maior ou menor incidência de perdas por mortalidade durante estas épocas.

No geral, as fases de verão e de primavera, ou os dias mais quentes do ano, oferecem as piores condições térmicas para o transporte. Considera-se nesta etapa, o efeito do jejum, sendo a restrita a reserva energética das aves para enfrentar esta situação de estresse térmico. Desta forma, a mortalidade acima dos limites normais é comumente observada nesta época quente, $40 \%$ maior em relação às demais estações (Petracci et $a l .$, 2006). Na primavera e no outono, por serem consideradas estações de transição, a preocupação quanto ao estresse térmico não são menos importantes, visto que as flutuações térmicas são esperadas nestes meses (Nääs et al., 2001). As mesmas considerações acima podem ser transpostas para os horários quentes do dia, ou seja, do final da manhã até o final da tarde.

No inverno e no outono, ou mesmo em períodos mais frios do dia, a temperatura e umidade relativa se enquadram geralmente na faixa de conforto térmico para as aves. Desta forma, espera-se uma reduzida mortalidade neste período, quando comparada com o verão. Mesmo assim, deve-se ter a devida atenção e acompanhamento quanto à variação térmica neste período. Apesar dos efeitos do inverno não terem sido evi- dentes na pesquisa realizada por Warriss et al. (2005), Hunter et al. (1999) observaram sintomas de hipotermia severa em aves transportadas sob frio intenso.

\section{DISTÂNCIA GRANJA-ABATEDOURO}

A distância possui grande influência na sobrevivência das aves. Com o aumento do trajeto, os animais ficam expostos durante mais tempo aos agentes estressores, principalmente às condições ambientais. Por isto, em diversos estudos têm sido observado que quanto maior a distância de transporte, maior foi o número de aves mortas na chegada ao abatedouro (Warriss et al., 1990; Vecerek et al., 2006; Barbosa Filho, 2008; Vieira, 2008). Voslarova et al. (2007) encontraram resultados de mortalidade elevados em distâncias acima de $100 \mathrm{~km}$, sendo que a menor proporção de aves mortas encontrada $(0,6 \%)$ foi registrada em distâncias abaixo de $50 \mathrm{~km}$. Este aumento das perdas relacionado com o aumento da distância se deve à significativa redução da habilidade do animal em manter o equilíbrio fisiológico necessário para a sua adaptação ao transporte. No entanto, dada a dificuldade em se manter a uniformidade quanto à localização das granjas, para muitas empresas torna-se inviável a restrição da distância granjaabatedouro.

Uma tabela prática é apresentada por Barbosa Filho (2008) quanto à variação da mortalidade (tabela II), de acordo com as combinações de tempo, distância e velocidade de transporte. Porém deve-se considerar que a mortalidade das aves não depende somente das condições observadas durante o transporte, outros fatores também podem estar contribuir para a variação destes valores.

Verifica-se um aumento da mortalidade das aves para combinações de tempos e distâncias maiores. Conforme o exemplo do ocorrido também em outras estações do ano estudadas, a combinação de maiores distâncias, tempos de transporte com velocidades maiores parecem promover uma re- 
dução na mortalidade. Esta redução, por sua vez, deve ser resultante de uma maior circulação de ar ao longo da carga promovida por uma maior ventilação resultante do aumento da velocidade do caminhão.

A escolha das granjas para o transporte pré-abate das aves é o primeiro fator a ser decidido e por isto possui destacada importância no bem-estar das aves durante o mesmo. No entanto, a escolha deve ser pautada nas condições climáticas da região e no período do dia. Para isto, o responsável pelo planejamento deve estar mais atento com a previsão do tempo, visando às melhores condições para cada trajeto.

Seja nos meses mais quentes ou frios, o período da tarde é o mais problemático para o transporte, com relação ao estresse térmico das aves (Nijdam et al., 2004; Vieira, 2008; Barbosa Filho et al., 2009, Simões et $a l ., 2009)$. Desta forma, durante este turno, as distâncias a serem percorridas devem ser menores, ou seja, abaixo de $25 \mathrm{~km}$, para evitar a ação prolongada das variáveis ambientais sob as aves. As distâncias maiores devem ser percorridas no período da noite e no início da manhã, pois, geralmente são períodos diários mais confortáveis sob o ponto de vista térmico.

No entanto, durante os meses e horários do dia mais frios, deve-se tomar o cuidado com o estresse térmico por frio das aves durante a noite e manhã, principalmente na região da carga com maior contato com o

Tabela II. Variação da mortalidade (+: maior e-: menor), em função das combinações entre tempo, distância e velocidade de transporte. (Mortality variation (+: high and -: low), in relation with the combination between time, distance and transport velocity).

\begin{tabular}{llc}
\hline & + Tempo & + Distância \\
\hline+ Distância & + mortalidade & - \\
+ Velocidade & - mortalidade & - mortalidade \\
\hline
\end{tabular}

(Fonte: Barbosa Filho, 2008). vento (caixas frontais e superiores da carga, por exemplo). Assim, o motorista deve estar atento quanto ao uso de lonas plásticas nesta região da carga, evitando que o lote apresente hipotermia severa e conseqüentemente, mortalidade elevada na chegada.

\section{QuALIDADE DAS ESTRADAS E VIBRAÇÃO DA CARGA}

As estradas exercem impactos consideráveis na carga, fato este que deve ser considerado no planejamento de um transporte de frangos de corte. No caso de estradas de terra, a irregularidade das pistas oferece outra influência nas aves pouco conhecida, que é a vibração da carga. Dependendo das condições das vias de transporte, a qualidade da carcaça e conseqüentemente da carne poderão estar sendo comprometidas. A quantidade de solavancos, pancadas e vibrações a que a carga estará sendo submetida poderá afetar a qualidade do produto final e contribuir para o aumento total das perdas ao longo da etapa de transporte. Sem contar ainda que quanto pior a condição da estrada maior será o tempo gasto na viagem e conseqüentemente, maior será também o tempo em que os animais ficarão expostos às condições ambientais.

Alguns autores discutiram os efeitos da vibração em frangos de corte. Randall et al. (1997) afirmaram que as aves normalmente ficam deitadas durante o transporte, permitindo que a vibração atue inicialmente no peito e nos músculos da perna, sendo transmitido posteriormente para as demais partes do corpo. No entanto, no caso de choques bruscos em estradas irregulares, podem-se considerar danos na carcaça e na estabilidade postural nos animais. Além disso, outras respostas fisiológicas indicam estresse severo quando a vibração atua negativamente no bem-estar das aves durante o transporte, principalmente danos musculares e hipoglicemia (Carlisle et al., 1998). No entanto, Abeyesinghe et al. (2001) e posteriormente Garcia et al. (2008), não 


\section{SILVAE VIEIRA}

encontraram evidências significativas quando analisado o efeito conjunto da vibração com outros fatores de estresse, como a temperatura elevada. Isto indica a necessidade de ampliar as combinações de variáveis para se ter um quadro mais preciso do estresse das aves quando submetidas às diferentes vibrações.

Os motoristas talvez sejam as pessoas mais ligadas ao controle da operação de transporte das aves, pois são os responsáveis pela condução dos animais ao longo do trajeto da granja até o abatedouro. Eles deverão estar sempre atentos a tudo o que se passa com a carga que estão transportando, uma vez que se houver realmente um comprometimento com a integridade da carga transportada isso resultará em uma melhor qualidade final do produto que chegará ao abatedouro.

Pontos importantes que poderão ser observados pelos motoristas dos caminhões estão relacionados com a verificação das condições ambientais antes e durante a viagem, verificação das condições das vias por onde deverá trafegar e observação constante e periódica de toda a carga com o objetivo de antecipar algum problema que possa vir a ocorrer.

\section{A ESPERA NO ABATEDOURO}

A importância da espera se resume em oferecer, dentro de um espaço de tempo adequado, condições térmicas satisfatórias para manter o animal em conforto após o transporte e até a chegada na linha do abate. Neste contexto, a espera deve atender este objetivo perante as diferentes condições ambientais, horários do dia, da logística de transportes e do fluxo de abate. Com base na condição climática brasileira, a preocupação com o ambiente onde se encontram os caminhões na espera é primordial, pois todos os cuidados nas primeiras operações pré-abate poderão ser perdidos se a espera no abatedouro não for adequada.

Tanto a nebulização quanto a ventilação devem ser bem distribuídas ao longo da sala de espera, com o correto acionamento das mesmas e de forma racional, sem desperdício de água e energia. Nota-se, na maioria dos casos, que tal recomendação não é padronizada, pois pouca importância é dada para esta etapa. Desta forma, observamse salas de espera sem um bom gerenciamento de controle ambiental, outras sem nenhum recurso e, em casos mais críticos, a espera consiste em manter os caminhões expostos a céu aberto, sem a preocupação com a excessiva exposição dos mesmos às variáveis meteorológicas, ocasionando grandes perdas ao final do processo produtivo.

\section{Perdas na etapa de espera no ABATEDOURO}

O objetivo de um ambiente de espera num abatedouro consiste em prover as melhores condições térmicas para as aves, diminuindo as chances de perda por mortalidade durante esta etapa. Isto pode ser explicado pela impossibilidade do abate imediato, ou seja, a logística perfeita entre a granja e a linha de abate. Na maioria dos casos, além de eventuais problemas, como por exemplo, falhas mecânicas na linha de abate, a saída de muitos caminhões de uma mesma granja indica a necessidade de mantê-los dentro da empresa, aguardando a ordem de descarga das aves na linha de abate. Algumas poucas empresas ainda se preocupam com a distância percorrida pelos caminhões, mantendo um ordenamento na chegada e saída de caminhões do galpão de espera.

No entanto, devido à escassez de informações quanto ao tratamento ideal a ser dado às aves nesta etapa, Hunter et al. (1998) afirmaram que a espera nos abatedouros tem sido uma fonte potencial de estresse para os frangos. Os mesmos autores evidenciaram que há um aumento de $10^{\circ} \mathrm{C}$ no interior da carga transportada quando o tempo de espera excede 2 horas em galpões com pouca climatização. Quando comparados ambientes de espera com e pouca climatização, os 
galpões os quais apenas tinham ventiladores apresentaram maiores percentagens de aves mortas (acima de 0,6\%) em relação aos ambientes com climatização eficiente, utilizando ventiladores e nebulizadores (Bayliss e Hinton, 1990). A partir daí, problemas mais graves podem ocorrer, como por exemplo, hemorragia nos músculos, perdas qualitativas na carne e mortalidade (Kranen et al., 1998). Apesar de não existir uma estimativa confiável do número de aves mortas apenas na espera, Ritz et al. (2005) informaram que $40 \%$ das perdas pré-abate são ligadas ao estresse térmico, seja por frio ou calor. Esta informação assume grande importância no Brasil, onde a média de temperatura e umidade relativa ao longo do ano é elevada na maioria das regiões, em contrapartida à ineficiência térmica das instalações utilizadas na avicultura.

\section{PONTOS CRítICOS NA ETAPA DE ESPERA - CONDIÇÕES CLIMÁTICAS}

As variações térmicas em uma dada região ao longo do ano, bem como durante os períodos do dia (manhã, tarde e noite) influenciam sobremaneira o bem-estar e o conforto das aves durante a espera no abatedouro. Bayliss e Hinton (1990), ao comparar dois tipos de galpões de espera (alta e baixa climatização), também avaliaram a mortalidade dos frangos em diferentes estações do ano e encontraram percentagens por volta de 0,56 e $0,64 \%$ para a primavera e verão, respectivamente, em ambientes com pouca climatização.

Quanto à influência do ambiente externo, a temperatura e umidade relativa elevada aumentam a preocupação pela adoção de climatização na fase de espera (Quinn et al., 1998; Ritz et al., 2005; Barbosa Filho, 2008; Vieira, 2008). Quando transportadas em conforto térmico (entre 15 e $22^{\circ} \mathrm{C}$ ), as aves não apresentam alterações fisiológicas, ao contrário daquelas mantidas durante 2 horas em caixas de transporte à $34^{\circ} \mathrm{C}$, as quais apresentaram um aumento no nível de estresse (Aksit et al., 2006). O caminhão em movimento proporciona uma relativa ventilação, favorecendo a redução da carga térmica no lote. No entanto, com a carga parada durante a espera, a sensação térmica dos frangos piora ainda mais, devido à produção de calor e vapor d'água dos animais. Segundo Kettlewell et al. (2000), um aumento na umidade relativa de 20 para $80 \%$ acarreta aumento de 0,42 por hora no núcleo térmico corporal dos animais. Isto significa um esgotamento fisiológico intenso, diminuindo as reservas energéticas que o animal possui para enfrentar tal situação. Se não forem tomados os devidos cuidados com a ambiência nesta fase de espera, ou seja, a preocupação quanto à climatização bem planejada e controlada nos galpões, por exemplo, as chances de mortalidade aumentam ao longo do tempo.

\section{DISTÂNCIA GRANJA-ABATEDOURO}

A distância é outro fator que influencia bastante na condição de espera pré-abate, pois determina a decisão a ser tomada quanto ao uso da climatização, bem como a intensidade dada pelo tempo em que os caminhões aguardam no galpão. No entanto, seu maior efeito é observado no estresse fisiológico das aves, culminando no aumento da mortalidade durante a etapa de espera.

Conforme relatado por Bressan e Beraquet (2002), as aves apresentam um desgaste acentuado das reservas energéticas nos primeiros 30 minutos de exposição ao estresse, também considerado como primeira fase de estresse. Comparativamente às operações pré-abate, isto se dá logo após o carregamento na granja, onde os animais já experimentam tipos diversos de estresse. Neste momento, a ave possui uma reserva que é rapidamente consumida, culminando logo após numa adaptação ao estresse. Todavia, tal efeito adaptativo não acontece nas primeiras horas de transporte, portanto as aves são encaminhadas ao abatedouro bastante debilitadas quanto aos parâmetros qualitativos.

Vale considerar que, em muitos abate- 


\section{SILVAE VIEIRA}

douros, a rotina entre a espera e o descarregamento das caixas na linha de abate ainda demanda certo tempo, agravado por possíveis problemas na linha de abate ou devido ao excesso de caminhões a serem abatidos. Desta forma, boa parte das aves pode chegar à mortalidade antes da pendura, em face da debilidade apresentada anteriormente.

Já em distâncias maiores, as aves já passaram pelo período mais crítico de estresse durante o transporte e o organismo ativa os mecanismos de adaptação, o que retarda a implantação de um processo irreversível. Todavia, a reposição das reservas energéticas não ocorre com o prolongamento do tempo de espera, e com este intervalo, aumentam-se as chances de mortalidade elevada no lote. Em termos de perdas qualitativas, os autores encontraram redução na qualidade da carne e aumento da mortalidade em distâncias mais longas do que em distâncias mais curtas (Warriss et al., 1992; Bressan e Beraquet, 2002; Vecerek et al., 2006; Barbosa Filho, 2008; Vieira, 2008).

\section{TEMPO DE ESPERA}

O tempo de espera é um dos fatores de maior variação nos abatedouros, com pouca padronização quanto ao intervalo de tempo ideal que proporcione uma condição precisa de conforto térmico para os animais nos ambientes de espera. Tanto o conforto quanto o estresse térmico possuem efeito direto na qualidade do produto, quando associados com o fator tempo (Fraqueza et al., 1998). Sem dúvida, este é o principal fator nesta etapa que determina a eficiência da climatização como agente de remoção de calor das aves.

Hunter et al. (1998) afirmaram que o tempo em galpões de espera pode exceder ou igualar ao tempo gasto no transporte. Esta amplitude temporal indica a falta de controle quanto ao tempo gasto nesta operação. Apesar de que a ventilação foi aplicada aos animais como medida para retirar calor dos mesmos, os autores indicaram que este controle depende da avaliação subjetiva do controlador, portanto, com baixo nível de manejo climático.

Alguns autores demonstraram que ambientes de maior estresse para os frangos foram aqueles que tiveram um tempo de espera menor, ou seja, nas primeiras duas horas durante dias em que a temperatura esteve elevada, concluindo que não basta apenas trabalhar com o tempo de espera isoladamente. O controle ambiental é necessário para reduzir os efeitos negativos do ambiente externo no bem-estar das aves (Quinn et al., 1998; Silva et al., 1998; Bressan e Beraquet, 2002; Barbosa Filho, 2008; Vieira et al., 2007; Vieira, 2008). Em contrapartida, outros autores não evidenciaram o mesmo, indicando que a elevada mortalidade esteve associada com intervalos de tempo maiores de espera, isto é, os caminhões devem aguardar o menor tempo possível dentro dos galpões, sendo o ideal o abate imediato destas aves (Hunter et al., 1998; Warriss et al., 1999). No entanto, os mesmos autores pesquisaram galpões com poucos ventiladores, o que influi diretamente no conforto e sobrevivência das aves nesta fase final pré-abate. Ou seja, existe uma divergência quanto às recomendações, o que dificulta o bom planejamento do manejo bioclimático e do tempo a ser adotado, durante o qual as aves serão mantidas nestes galpões.

\section{AdEQUAÇÃo do GALPÃO PARA A ETAPA DE ESPERA}

O local onde os caminhões permanecerão estacionados antes do abate deve oferecer às aves condições de trocas térmicas com o ambiente e por isto, alguns detalhes construtivos devem ser observados.

O galpão deve ser climatizado para se atingir o objetivo de bem-estar e conforto térmico das aves. Para isto, a instalação de linhas de ventilação intercaladas com nebulização é importante para este fim, 
sendo estas distribuídas uniformemente (teto e pilares do galpão), visando dentro do possível climatizar igualmente todas as caixas. Deve também possuir espaço para todos os caminhões e normalmente esta determinação é feita de acordo com o fluxo de abate da empresa e com o tempo médio de espera a ser adotado. A caixa d'água que abastece o sistema de nebulização deverá ser protegida de incidência direta de raios solares. A proteção lateral contra radiação solar direta deve ser feita por meio de telas do tipo sombrite e o material de cobertura do galpão deve permitir a reflexão destes raios visando a redução da carga térmica do ambiente (figura 3).

Conjuntamente com todos estes fatores, a programação de manejo é essencial, sendo necessária a elaboração de um roteiro de ações a serem tomadas, disponíveis aos operadores do galpão, com o objetivo de sistematizar a informação e torná-la conhecida para todos os envolvidos nesta atividade. A comunicação é muito importante, para facilitar a tomada rápida de decisão, no caso de problemas e atrasos ao longo das demais operações pré-abate.

\section{MANEJO E CONTROLE DA CLIMATIZAÇÃONO GALPÃO DE ESPERA}

Os principais fatores bioclimáticos a serem observados fora e dentro de um galpão de espera consistem na temperatura e umidade relativa. Visando o controle destas variáveis, a instalação de um termohigrômetro é necessária para o acompanhamento periódico da condição térmica dos ambientes. Este equipamento consiste em um medidor conjunto de temperatura e umidade relativa, de fácil observação e registro. Atualmente no mercado, existem diversos tipos destes aparelhos, desde termômetros de mercúrio (bulbo seco e úmido), incluindo também os automáticos

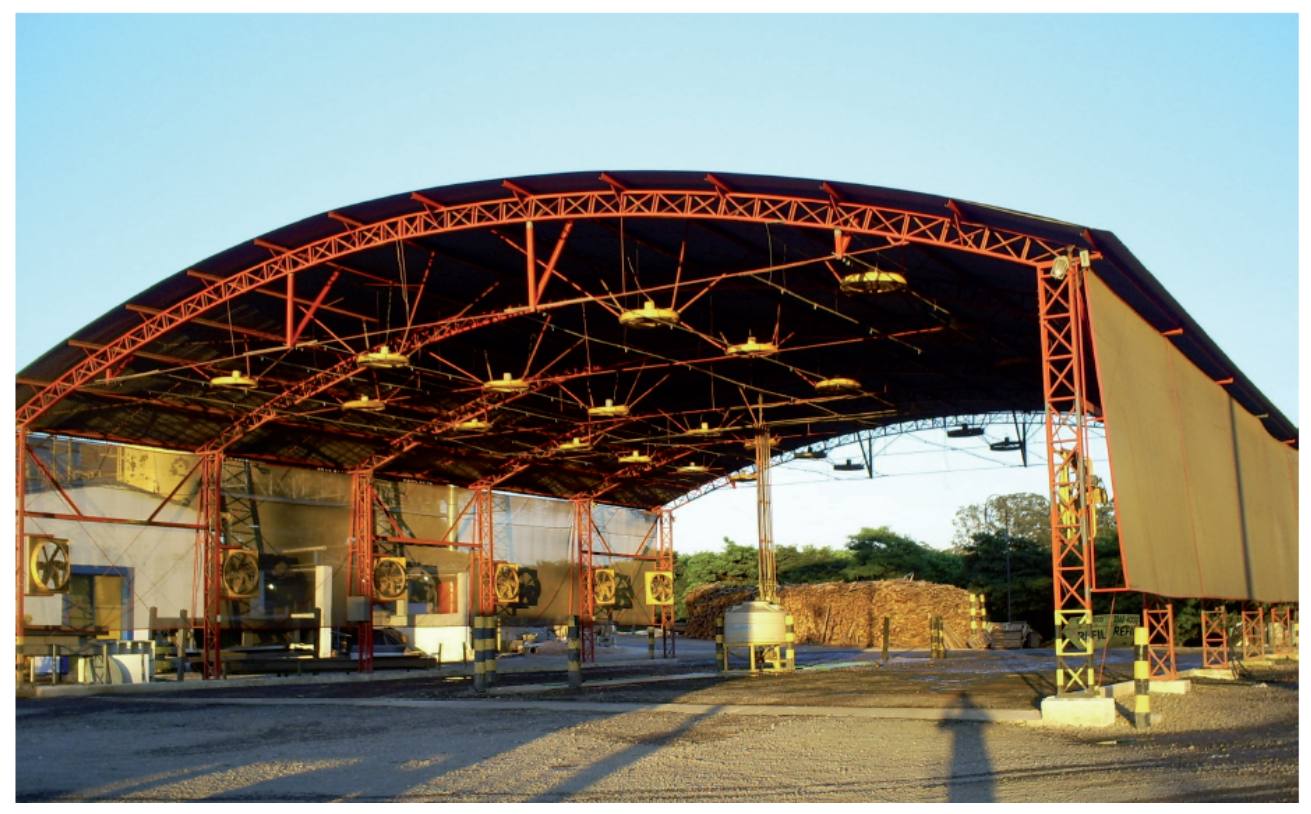

Figura 3. Exemplo de um galpão de espera de um abatedouro comercial de frangos de corte. (Vieira, 2008). (An example of a holding area in a commercial broiler slaughterhouse (Vieira, 2008)). 


\section{SILVAE VIEIRA}

(data loggers), cuja aquisição de dados é programável dentro do intervalo de tempo que se deseja obter os dados.

A localização do termohigrômetro deve ser feita com bastante critério, evitando assim coletas de dados que não representem o ambiente. Dadas as dimensões do galpão de espera, o ideal é que tenha um em cada lateral do galpão, bem como no centro geomé- trico do mesmo, à altura do meio da carga, para que toda a área seja bem amostrada, visando uma avaliação completa do local. A leitura deve ser feita periodicamente, de preferência de hora em hora, permitindo o acionamento e desligamento da ventilação e nebulização. Nesta função, o operador deve ser treinado adequadamente, para que ele tenha o discernimento de avaliar a

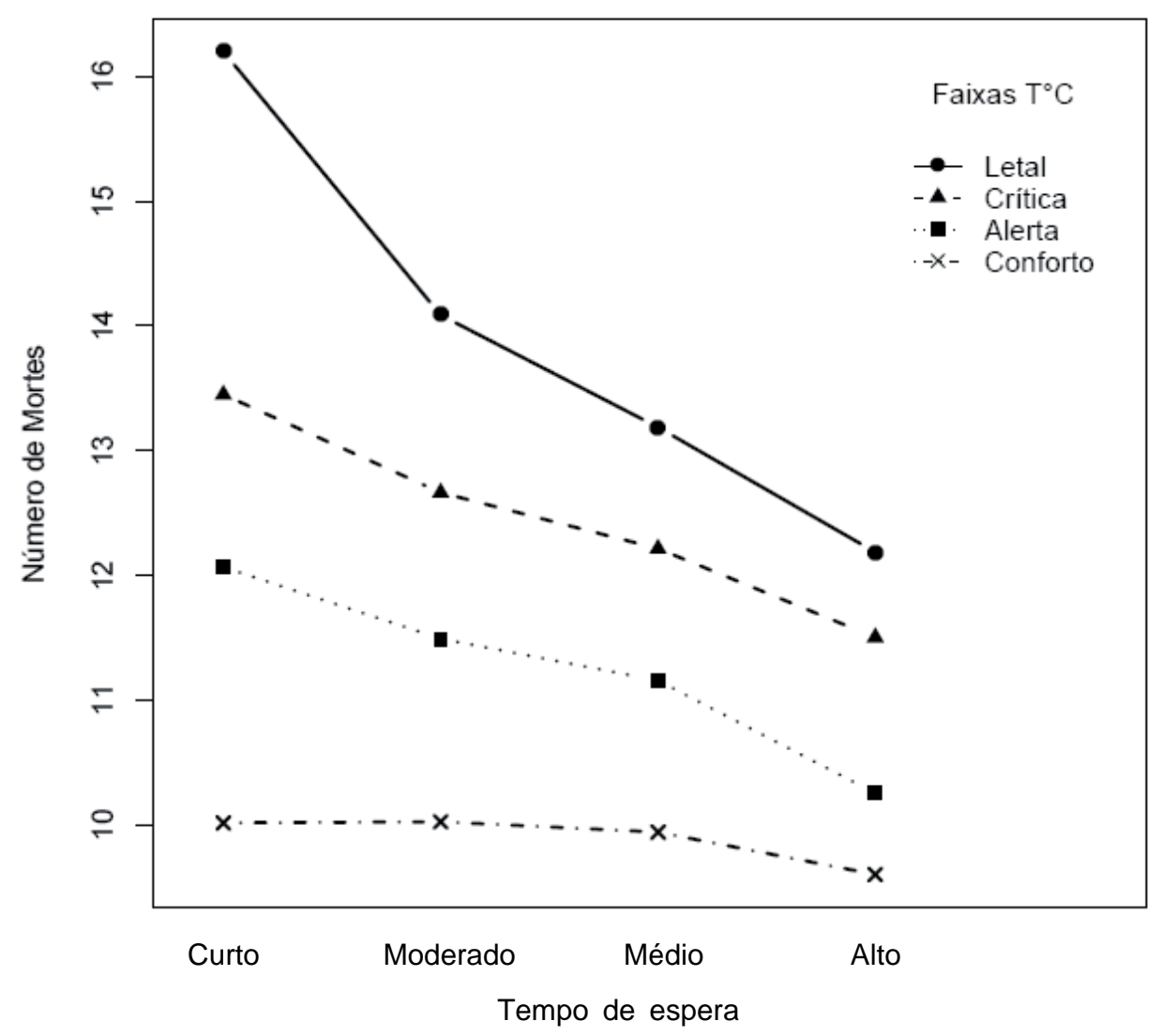

Figura 4. Interação entre o tempo de espera no abatedouro e as faixas de temperatura, em relação ao número de aves mortas, onde Curto: abaixo de 1 hora, Moderado: 1 - 2 horas, Médio: 2 - 3 horas, Alto: acima de 3 horas, e as faixas de temperatura: Conforto: abaixo de $21^{\circ} \mathrm{C}$; Alerta: $22-24^{\circ} \mathrm{C}$; Critica: $25-28^{\circ} \mathrm{C}$; Letal: acima de $28^{\circ} \mathrm{C}$ (Vieira, 2008). (Interaction between lairage time at the slaughterhouse and the temperature ranges, in relation to the number of dead birds, which Curto: lower than 1 hour, Moderado: from 1 to 2 hours, Médio: from 2 to 3 hours, Alto: higher than 3 hours, and the temperature ranges: Conforto: lower than $21^{\circ} \mathrm{C}$, Alerta: from 22 to $24^{\circ} \mathrm{C}$, Crítica: from $25-28^{\circ} \mathrm{C}$, Letal: higher than $28^{\circ} \mathrm{C}$ (Vieira, 2008)).

Archivos de zootecnia vol. 59 (R), p. 126. 
situação e conduzir ações que auxiliem no conforto térmico das aves.

\section{A ASPERSÃO DE ÁGUA DURANTE O DESCAN- SONOFRIGORÍFICO}

O mesmo problema ocasionado durante a etapa de carregamento das aves também atinge a fase de espera no abatedouro, ou seja, a falta de informação a respeito das condições ideais para se efetuar a aspersão de água na carga. Mesmo com o galpão climatizado, observa-se a atividade sendo realizada sem critérios, tanto nos horários quentes, quanto naqueles onde a temperatura está abaixo do limite de conforto das aves. Além do gasto desnecessário de água, o resultado disto é a elevada mortalidade durante esta etapa nos horários mais frios, devido à falta de controle quanto à climatização do galpão de espera.

Para contornar este problema, o operador deve estar atento às condições ambientais as quais as aves são submetidas, fora ou dentro do galpão de espera. A aspersão de água deverá ser realizado quando a umidade relativa do ar estiver abaixo de $50 \%$ e com a temperatura elevada. Fora deste intervalo, o controle adequado dos ventiladores e nebulizadores são suficientes para atender as exigências térmicas dos animais nestas condições. No inverno ou em dias e horários mais frios, deve ser suspensa a atividade, para não provocar estresse por frio nas aves (Barbosa Filho, 2008; Vieira, 2008).

A distribuição de água também é outro fator importante, devendo ser feito atentamente a aspersão de água uniforme ao longo da carga, sem manter a mangueira ligada durante muito tempo em poucos pontos, evitando aves excessivamente molhadas, dificultado as trocas térmicas, e outras praticamente secas, mantendo o estresse térmico prolongado.

\section{O CONTROLEDOTEMPODE ESPERA}

Para cada fator influente na proporção de aves mortas antes do abate, como por exemplo, temperatura externa ao galpão e distância granja-abatedouro, existe uma recomendação quanto ao tempo de espera. Cabe à empresa escolher qual destas variáveis possui o maior peso na mortalidade. Em pesquisa recente realizada por Vieira (2008), foram analisadas com detalhes as relações entre os fatores envolvidos nas operações pré-abate com o tempo de espera.

Em relação à temperatura externa, quanto maior os valores ao longo do dia e do ano, maior a necessidade do tempo de espera para as aves, desde que o ambiente seja devidamente climatizado (ventiladores, nebulizadores e ocasionalmente a aspersão de água) (figura 4).

Com o passar do tempo, os efeitos da climatização chegam às aves ao longo da carga, possibilitando às mesmas a perda de calor para um ambiente mais confortável. Além disso, quanto mais quente o ambiente externo, os animais se tornam cada vez mais sensíveis à mudança benéfica de condição ambiental, possibilitando menores chances de mortalidade no lote. Intervalos de tempo de espera menores devem ser adotados quando as temperaturas se encontram mais amenas ou até mesmo baixas, devido ao risco de estresse por frio, o que ocasionará aumento na mortalidade ao longo do tempo.

Quanto às diferentes distâncias entre as granjas e o abatedouro, os maiores percursos (acima de $51 \mathrm{~km}$ ) estão relacionados com a permanência curta no galpão de espera (figura 5)

Como as aves já ultrapassaram a primeira fase de estresse, conforme relatada por Bressan e Beraquet (2002), os animais ao chegarem ao abatedouro já passaram à irreversibilidade do quadro de estresse, em função do esgotamento das reservas energéticas. Com isto, se tornam insensíveis ao tratamento climático dado na espera préabate e quanto maior o tempo aumenta-se o número de aves mortas no caminhão. Neste caso, recomenda-se o menor tempo possível entre a chegada do caminhão ao abatedouro e a linha de abate (abaixo de 2 horas). Para 


\section{SILVAEVIEIRA}

distâncias menores (abaixo de $24 \mathrm{~km}$ ), as aves ainda se encontram em condições de reversão do quadro de estresse e desta forma, as aves respondem efetivamente aos efeitos da climatização. Portanto, para trajetos menores, intervalos de tempo acima de 3 horas auxiliam na redução de perdas por mortalidade (tabela III).

No geral, considerando conjuntamente todos os fatores que influem nas perdas préabate e relacionando os mesmos com o tempo de espera a ser adotado, a recomendação visando esta redução de perdas é de 2 horas de espera, variando entre 1 e 3 horas. Este intervalo de tempo abrange os benefícios promovidos pela climatização no galpão de espera e conseqüentemente, o retorno parcial ou total à condição de conforto térmico das aves.

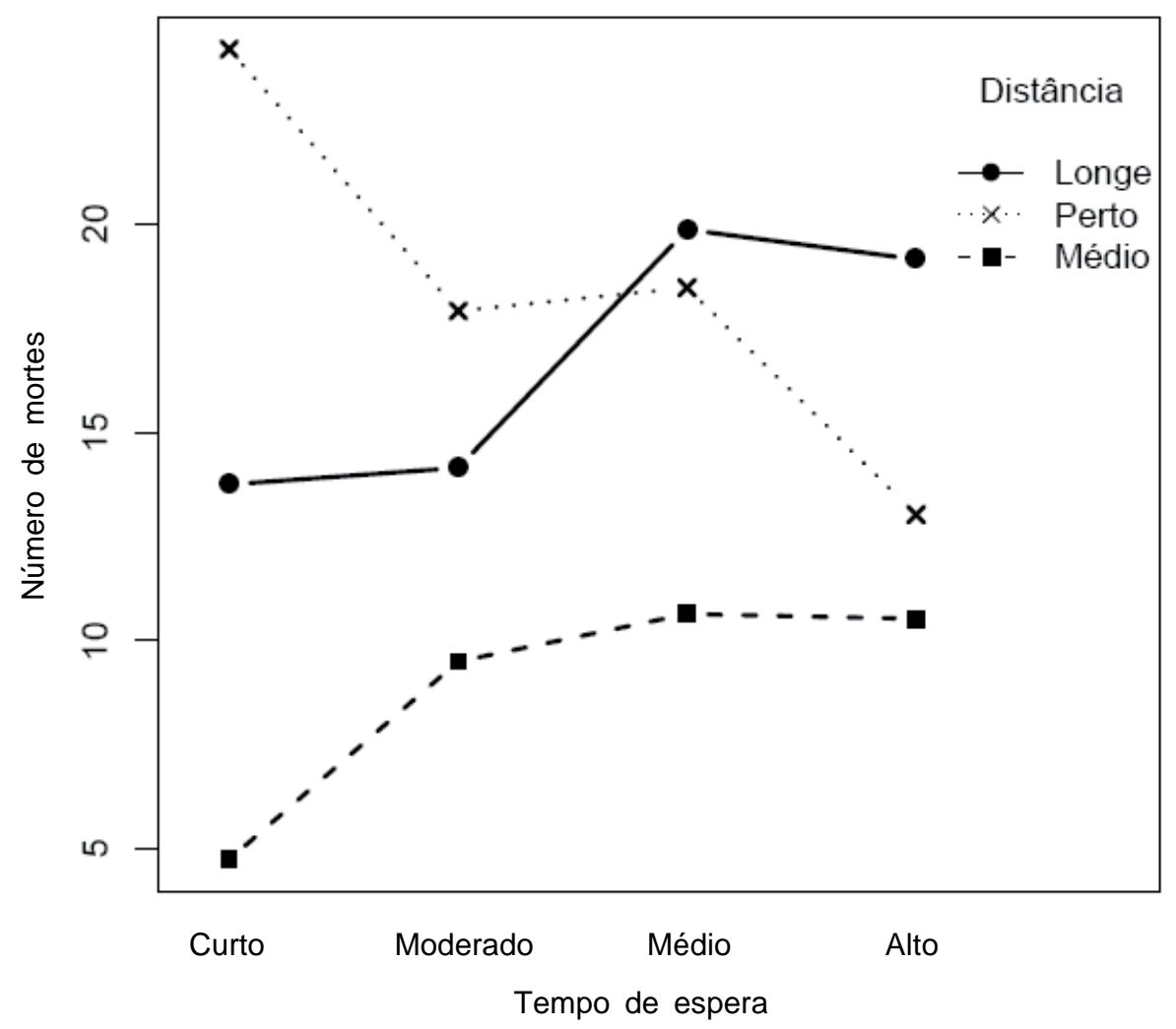

Figura 5. Valores médios da interação entre a distância granja-abatedouro e os diferentes intervalos de tempo de espera, em relação ao número de aves mortas, sendo intervalos de tempo de espera: Curto: menor que 1 hora, Moderado: 1 - 2 horas, Médio: 2 - 3 horas, Alto: acima de 3 horas e faixas de distância: Longe: acima de $51 \mathrm{~km}$; Médio: $25-50 \mathrm{~km}$; Perto: abaixo de $24 \mathrm{~km}$ (Fonte: Vieira, 2008). (Mean values of the interaction between distance from farm to the slaughterhouse and the different lairage time ranges, in relation to the number of dead birds, with the following lairage time ranges: Curto: lower than 1 hour, Moderado: from 1 to 2 hours, Médio: from 2 to 3 hours, Alto: higher than 3 hours and the distance ranges: Longe: higher than $51 \mathrm{~km}$; Médio: from 25 to $50 \mathrm{~km}$; Perto: lower than $24 \mathrm{~km}$ (Vieira, 2008)). 
Tabela III . Valores recomendados do tempo de espera em distância granja-abatedouro e suas respectivas taxas de mortalidade esperadas. (Recommended values of lairage time in relation to distance between farm and slaughterhouse and its respective expected mortality rates (\%)).

\begin{tabular}{lcc}
\hline Distância & Tempo de espera (faixas) & \% mortalidade esperada \\
\hline Longe (acima de $51 \mathrm{~km}$ ) & Moderado (entre 1 e 2 horas) & 0,41 \\
Médio (entre 25 e $50 \mathrm{~km}$ ) & Curto (abaixo de 1 hora) & 0,12 \\
Perto (abaixo de $24 \mathrm{~km}$ ) & Alto (acima de 3 horas) & 0,41 \\
\hline
\end{tabular}

(Fonte: Vieira, 2008).

\section{CONSIDERAÇÕESFINAIS}

Em função dos dados apresentados neste texto, verifica-se que a ambiência préabate está associada a novos paradigmas inclusive com a "Logística de distribuição" de cargas vivas, o que ainda hoje é um problema para os profissionais que atuam em administração de empresas e engenharia de produção.

O entendimento da ambiência como fator de redução de mortalidade de animais e bem-estar animal até a fase final da exploração é um assunto ainda incipiente

\section{BIBLIOGRAFIA}

Aksit, M., Yalçin, S., Özkan, S., Metin, K. and Özdemir, D. 2006. Effects of temperature during rearing and crating on stress parameters and meat quality or broilers. Poult. Sci., 85: 18671874.

Abeyesinghe, S.M., Wathes, C.M., Nicol, C.J. and Randall, J.M. 2001. The aversion of broiler chickens to concurrent vibrational and thermal stressors. Appl. Anim. Behav. Sci., 73: 199215.

Bayliss, P.A. and Hinton, M.H. 1990. Transportation of broilers with special reference to mortality rates. Appl. Anim. Behav. Sci., 28: 93-118.

Barbosa Filho, J.A.D. 2008. Caracterização quantiqualitativa das condições bioclimáticas $e$ produtivas nas operações pré-abate de frangos de corte. 2008. Tese (Doutorado em Física do Ambiente Agrícola). Escola Superior de Agricultura "Luiz de Queiroz". Universidade de São cuja necessidade de novos estudos deverá em futuro próximo definir toda a logística de distribuição entre empresas integradoras e granjas integradas. Em função da região do país e das condições climáticas regionais poderão por meio de ferramentas computacionais reduzirem os índices de perdas localizadas nessas etapas com tomadas de decisão mais eficiente. Deve-se considerar também que esse raciocínio estende-se para outras cadeias produtivas como a suinocultura, bovinocultura dentre outras.

Paulo. Piracicaba, $174 \mathrm{pp}$

Barbosa Filho, J.A.D., Vieira, F.M.C., Silva, I.J.O., Garcia, D.B., Silva, M.A.N. and Fonseca B.H.F. 2009. Transporte de frangos: caracterização do microclima durante o inverno. Rev. Bras. Zootecn., 38: 2442-2446.

Bressan, M.C. and Beraquet, N.J. 2002. Efeito de fatores pré-abate sobre a qualidade da carne de peito de frango. Ciênc. Agrotéc., 26: 10491059.

Broom, D.M. 1986. Indicators of poor welfare. Br. Vet. J., 142: 524-526.

Broom, D.M. 1993. Welfare assessment and welfare problem areas. In: Grandin, T. (Ed.). Livestock Handling and Transport. Wallingford. CAB International. $320 \mathrm{pp}$.

Broom, D.M. 1998. Welfare, stress and evolution of feelings. Adv. Stud. Behav., 27: 371-403.

Carlisle, A.J., Mitchell, M.A., Hunter, R.R., Duggan, 


\section{SILVAE VIEIRA}

J.A. and Randall, J.M. 1998. Physiological responses of broiler chickens to the vibrations experienced during road transportation. British Poult. Sci., S48-S49.

Delezie, E., Swennen, Q., Buyse, J. and Decuypere, E. 2007. The effect of feed withdrawal and crating density in transit on metabolism and meat quality of broilers at slaughter weight. Poult. Sci., 86: 1414-1423.

Fraqueza, M.J., Roseiro, L.C., Almeida, J., Matias, E., Santos, C. and Randall, J.M. 1998. Effects of lairage temperature and holding time on pig behaviour and on carcass and meat quality. Appl. Anim. Behav. Sci., 73: 317-330.

Furlan, R.L. and Macari, M. 2002. Termorregulação. In: Macari, M.; Furlan, R.L.; Gonzales, E. Fisiologia aviária aplicada a frangos de corte. FUNEP/UNESP. Jaboticabal. pp. 209-230.

Garcia, D.B., Silva, I.J.O., Barbosa Filho, J.A.D., Vieira, F.M.C. and Dias, C.T.S. 2008. Evaluation of the effect of vibration in simulated condition of transport of broiler chickens. VII International Livestock Environment Symposium. ILES VIII. Foz do Iguaçu.

Hunter, R.R. 1998. Physiological responses of broilers to pre-slaughter lairage: Effects of the thermal micro-environment? British Poult. Sci., 39: 53-54.

Hunter, R.R., Mitchell, M.A. and Matheu, C. 1997. Distribution of "dead on arrivals" within the bioload on commercial broiler transporters: correlation with climatic conditions and ventilation regimen. British Poult. Sci., 38: S7S9.

Hunter, R.R. 1998. Physiological responses of broilers to pre-slaughter lairage: Effects of the thermal micro-environment? British Poult. Sci., 39: 53-54.

Hunter R.R., Mitchell, M.A. and Carlisle, A.J. 1999. Wetting of broilers during cold weather transport: a major source of physiological stress? British Poult. Sci., 40: 48-49.

Hunter R.R., Mitchell, M.A. and Matheu, C. 2001. Mortality of broiler chickens in transit: Correlation with the thermal micro-environment. VI International Livestock Environment Symposium - ILES VI. Kentucky.

Kettlewell, P.J. 1989. Physiological aspects of broiler transportation. World's Poult. Sci. J., 46: 219-227.
Kettlewell, P.J., Hoxey, R.P. and Mitchell, M.A. 2000. Heat produced by broiler chickens in a commercial transport vehicle. J. Agr. Eng. Res., 75: 315-326.

Kranen, R.W., Veerkamp, C.H., Lambooy, E. and Van Kuppevelt, T.H. 1998. The effect of thermal pre-slaughter stress on the susceptibility of broiler chickens differing with respect to growth rate, age at slaughter, blood parameters, and ascites mortality, to hemorrhages in muscles. Poult. Sci., 77: 737-744.

Macari, M. and Furlan, R.L. 2001. Ambiência na produção de aves em clima tropical. In: Silva, I.J.O. Ambiência na produção de aves em clima tropical. Degaspari. Piracicaba. pp. 31-87.

Mitchell, M.A. and Kettlewell, P.J. 1998. Physiological stress and welfare of broiler chickens in transit: Solutions not problems! Poult. Sci., 77: 1803-1814.

Nääs, I.A., Miragliotta, M.Y., Aradas, M.E.C., Silva, I.J.O. and Baracho, M.S. 2001. Controle e sistematização em ambientes de produção. In: Silva, I.J.O. Ambiência na produção de aves em clima tropical. Degaspari. Piracicaba. pp. 165200.

Nicol, C.J. and Scott, G.B. 1990. Pre-slaughter handling and transport of broiler chickens. Appl. Anim. Behav. Sci., 28: 57-73.

Nijdam, E., Arens, P., Lambooij, E., Decuypere, E. and Stegeman, J.A. 2004. Factors influencing bruises and mortality of broilers during catching, transport, and lairage. Poult. Sci., 83: 16101615.

Paranhos da Costa, M.J.R. 2000. Ambiência na produção de bovinos de corte a pasto. An. Etol., 18: 3-15.

Paranhos da Costa, M.J.R. 2002. Ambiência e qualidade de carne. $5^{\circ}$ Congresso das Raças Zebuínas. Uberaba.

Petracci, M., Bianchi, M., Cavani, C., Gaspari, P. and Lavazza, A. 2006. Preslaughter mortality in broiler chickens, turkeys and spent hens under commercial slaughtering. Poult. Sci., 85: 16601664.

Quinn, A.D., Kettlewell, P.J., Mitchell, M.A. and Knowles, T. 1998. Air movement and the thermal micro climates observed in poultry lairages. British Poult. Sci., 39: 469-476.

Randall, J.M., Duggan, J.A., Alami, M.A. and White, R.P. 1997. Frequency weightings for the aversion 


\section{AMBIÊNCIA ANIMALE PERDAS PRODUTIVAS NO MANEJO PRÉ-ABATE: AVICULTURA}

of broiler chickens to horizontal and vertical vibration. J. Agr. Eng. Res., 36: 387-397.

Ritz, C.W. 2003. Reducing caching and livehaul DOA's. Poultry Digest Online, 4(1): 1-14. Disponível em: <http://www.wattnet.com/ library/DownLoad/PD104doa.pdf> (21-092005).

Ritz, C.W., Webster, A.B. and Czarick, M. 2005 Evaluation of hot weather thermal environment and incidence of mortality associated with broiler live haul. J. Appl. Poult. Res., 14: 594-602.

Silva, I.J.O., Lagatta, D., Pedroso, D., Piedade, S.M.S. and Nääs, I.A.. 1998. Avaliação do nível de conforto térmico para aves, durante a espera no abate, em função da localização dos caminhões transportadores. Conferência Apinco de Ciência e Tecnologia. Campinas.

Simões, G.S., Oba A., Matsuo, T., Rossa, A., Shimokomaki, M. and Ida, E.I. 2009. Vehicle thermal microclimate evaluation during Brazilian summer broiler transport and the occurrence of PSE (pale, soft and exsudative) meat. Braz. Arch. Biol. Technol., 52: 195-204.

Vecerek, V., Grbalova, S., Voslarova, E., Janackova, B. and Malena, M. 2006. Effects of travel distance and the season of the year on death rates of broilers transported to poultry processing plants. Poult. Sci., 85: 1881-1884.

Vieira, F.M.C., Barbosa Filho, J.A.D., Vieira, A.M.C., Garcia, D.B., Hildebrand, A. and Silva, I.J.O. 2007. Influência do tempo de espera pré-abate na temperatura retal de frangos de corte. Reunião Anual da Sociedade Brasileira de Zootecnia. Jaboticabal.
Vieira, F.M.C. 2008. Avaliação das perdas e dos fatores bioclimáticos atuantes na condição de espera pré-abate de frangos de corte. 2008. Dissertação (Doutorado em Física do Ambiente Agrícola). Escola Superior de Agricultura "Luiz de Queiroz". Universidade de São Paulo. Piracicaba, 176 pp.

Voslarova, E., Janackova, B., Vitula, F., Kozak, A. and Vecerek, V. 2007. Effects of transport distance and the season of the year on death rates among hens and roosters in transport to poultry processing plants in the Czech Republic in the period from 1997 to 2004. Vet. Med., 52: 262-266.

Warriss, P.D., Bevis, E.A., Brown, S.N. and Edwards, J.E. 1992. Longer journeys to processing plants are associated with higher mortality in broiler chickens. British Poult. Sci., 33: 201-206.

Warriss, P.D., Knowles, T.G., Brown, S.N., Edwards, J.E., Kettlewell, P.J., Mitchell, M.A. and Baxter, C.A. 1999. Effects of lairage time on body temperature and glycogen reserves of broiler chickens held in transport modules. Vet. Rec., 145: 218-212.

Warriss, P.D., Bevis, E.A. and Brown, S.N. 1990. Time spent by broiler chickens in transit to processing plants. Vet. Rec., 127: 617-619.

Warriss, P.D., Pagazaurtundua, A. and Brown, S.N. 2005. Relationship between maximum daily temperature and mortality of broiler chickens during transport and lairage. British Poult. Sci., 46: 647-651. 